\title{
Notas sobre o romance generativo "If on a winter's night a library cardholder"
}

\author{
Notes on the generative novel "If on a winter's night a library \\ cardholder"
}

\author{
Vinícius Carvalho Pereira ${ }^{a}$ \\ a Universidade Federal de Mato Grosso, Mato Grosso, Brasil - viniciuscarpe@gmail.com
}

Palavras-chave:

Romance generativo. NaNoGenMo.

Combinatória.

Distant reading.

\section{Keywords:}

Generative novel.

NaNoGenMo.

Combinatorics.

Distant reading.
Resumo: Realizamos no presente artigo uma análise de If on a Winter's Night a Library Cardholder, romance generativo desenvolvido por Robin Camille Davis para a edição de 2016 do NaNoGenMo - National Novel Generation Month. Considerando que o projeto de Davis envolvia uma releitura computacional de Se um viajante numa noite de inverno, discutimos aqui, à luz de escritos de Italo Calvino sobre o tema da combinatória, os sentidos advindos dos recursos técnicos mobilizados para a constituição de uma obra generativa de forte cariz metaliterário. Face aos desafios impostos à leitura de um romance produzido por uma máquina, procedemos também a um exercício de distant reading contrastivo entre If on a Winter's Night a Library Cardholder e a tradução para o inglês de Se um viajante numa noite de inverno, utilizando a aplicação web Voyant Tools. De tal modo, mapeamos números absolutos e relativos de palavras, bem como as relações que algumas delas contraem com as de sua adjacência, sobretudo termos do campo lexical do livro e da leitura, central nas obras de Calvino e Davis. Como contribuições à área de Estudos Literários, indicamos apontamentos relativos If on a Winter's Night a Library Cardholder e possíveis abordagens metodológicas para o estudo de romances generativos.

Abstract: This paper analyzes If on a Winter's Night a Library Cardholder, a generative novel developed by Robin Camille Davis for the NaNoGenMo National Novel Generation Month 2016 edition. Considering that Davis's project involved a computational re-reading of If on a Winter's Night a Traveler, we herein discuss, in the light of Italo Calvino's writings on combinatorics, the meanings arising from the technical resources used to produce such a highly metaliterary generative work. Due to the challenges of reading a novel produced by a machine, we also carry out an exercise of contrastive distant reading between If on a Winter's Night a Library Cardholder and If on a Winter's Night a Traveler, by means of the web app Voyant Tools. We thereby map absolute and relative numbers of words, as well as the relations some of them bear with others nearby, especially terms from the semantic field of books and reading, which are central in Calvino's and Davis's works. As contributions to the area of Literature Studies, we point out features of If on a Winter's Night a Library Cardholder and possible methodological approaches for the study of generative novels. 


\section{Combinatória de combinatória de combinatória...}

A história dos experimentos literários com operações combinatórias pode ser traçada de diferentes modos. Um primeiro deles enfatizaria a emergência bastante esparsa, em diferentes épocas, de textos em sua maioria poéticos, produzidos por permutação de signos, no que partiríamos dos anagramas latinos, passando pelas sextinas medievais, pelos jogos visuais barrocos, pelos labirintos oitocentistas, pelas vanguardas do século XX etc., até os dias de hoje. Alternativamente, poder-se-ia também concentrar o recorte temporal a partir de 1900, descrevendo mais detidamente a exploração sistemática de arranjos e combinações verbais em vanguardas das primeiras décadas do século, como o Dadaísmo e o Surrealismo; da metade dos novecentos, como a Poesia Experimental, o Concretismo e o Oulipo ${ }^{1}$; ou mesmo do final do século e das primeiras décadas do novo milênio, já com o uso de ferramentas digitais a potencializar as permutações sígnicas. Mais especificamente no âmbito da literatura eletrônica ${ }^{2}$, o desenvolvimento constante de softwares produtores de poemas com base em algoritmos de associação de elementos cadastrados em bancos de dados culminou na sedimentação de um gênero que ficou conhecido como "poesia generativa" (RETTBERG, 2019), poesia "gerada por computadores" (BARBOSA, 2001a), "motores textuais" (BARBOSA, 2001b), entre outras nomenclaturas.

Por outro lado, tanto no âmbito da literatura impressa quando da eletrônica, são menos comuns as empreitadas historiográficas da prosa combinatória. Esta conta com bem menos exemplares, muito possivelmente pela natureza precipuamente narrativa da prosa literária, a qual se estrutura por nexos causais entre as ações do enredo, em vínculos ora mais explícitos, dados na superfície do texto, ora mais implícitos, ou seja, a serem reconstituídos pelo leitor na interpretação. Num universo textual mais "amarrado" em termos de causalidade (isso sem tocarmos em pontos atinentes à extensão, à coerência e

\footnotetext{
${ }^{1}$ Ouvroir de Littérature Potentielle (em tradução livre, Oficina/Ateliê de Literatura Potencial), grupo de escritores e matemáticos que explora(va)m jogos de escrita a partir de restrições formais, criado na França na década de 60 .

${ }^{2}$ Conforme definição postulada pela Electronic Literature Organization (maior grupo mundial de estudos sobre o tema), a literatura eletrônica é composta de textos "com um aspecto literário importante que aproveita as capacidades e contextos fornecidos por um computador independente ou em rede" (HAYLES, 2009, p. 21).
} 
a outras características de horizontes de expectativa diante dos gêneros), torna-se mais difícil a experimentação combinatória com a prosa narrativa em comparação à lírica.

No caso de uma historiografia da ficção generativa, certamente seu estudo teria de se deter nos menos numerosos, mas ainda assim significativos exemplares textuais produzidos por membros do Oulipo, ainda em suporte impresso. Entre os projetos combinatórios narrativos do grupo francês, destacam-se dois textos de Raymond Queneau, um de seus fundadores: "Un conte à votre façon" (1973), hipertexto que permite a recombinação de algumas breves cenas sobre um dia na vida de três ervilhas; e Exercices de Style (1982), livro que reconta em 99 estilos diferentes, entre gustativo, onomatopaico, botânico, anagramático, anglicista e tantos outros, uma mesma anedota sobre um homem de chapéu e pescoço longo que entra no ônibus, discute com um passageiro e perde um botão do sobretudo. Ambos os textos, porém, valem mais como projetos conceituais do que propriamente como ficção: seus enredos e mundos narrativos são eclipsados pelo formalismo exacerbado, que ganha aí ares de pastiche.

Operando com uma ideia mais abrangente de combinatória - não exatamente de porções textuais invariáveis, mas sim de elementos e funções narratológicas -, Italo Calvino desenvolveu romances e contos em que a permuta constitui a mola matriz da organização do enredo, sem com isso prescindir da riqueza dos cenários, do clímax narrativo, ou da complexidade das personagens. Exemplos de tais obras do autor, para as quais há vasta fortuna crítica cuja retomada fugiria aos limites deste artigo, são os livros Se um viajante numa noite de inverno (2005), O castelo dos destinos cruzados (2006) e o conto "O incêndio da casa abominável” (2001), entre outros.

Sendo os textos oulipianos uma constante referência para o desenvolvimento da literatura eletrônica, sobretudo no que tange à ideia de uma produção textual programática e sistemática, não causa surpresa que a prosa combinatória produzida por computadores também retome frequentemente o repertório de escritores como Queneau e Calvino. Nesse sentido, destacamos, entre outros projetos na web, o de Robin Camille Davis (2016), que desenvolveu, com recursos digitais, o romance generativo If on a Winter's Night a Library Cardholder (em tradução livre, Se um titular de cartão de biblioteca numa noite de inverno), em clara releitura do texto calviniano Se um viajante numa noite de inverno. 
Nesse contexto, o presente artigo tem como objetivo a análise do romance generativo de Davis indagando os modos como este propõe, por expedientes algorítmicos combinatórios, um diálogo intertextual com o romance de Calvino e com obras de vários outros autores, processadas aleatória e automaticamente pelo sistema, conforme detalhado na próxima seção. Para tal estudo, procedemos a operações de close reading e distant reading (MORETTI, 2013) do texto de Davis e de alguns dos intertextos que este evoca, adotando ainda, como referenciais teóricos acerca da ideia de criação literária como exercício permutacional, postulações do próprio Calvino sobre o tema em textos ensaísticos e conferências. Desse modo, ao lermos, à luz dos escritos teóricos calvinianos sobre combinatória, uma obra de literatura digital também combinatória, a qual dialoga, por sua vez, com um romance calviniano também combinatório, entendemos realizar um gesto de retroalimentação entre os intertextos, um pouco aos moldes dos feedbacks entre máquinas caros à lógica da cibernética.

\section{(Re)combinando para ler de perto}

No célebre ensaio "Cibernética e fantasmas (notas sobre a narrativa como processo combinatório)", escrito inicialmente para uma conferência para a Associazione Culturale Italiana, em 1967, Calvino apresenta algumas de suas reflexões sobre a narrativa como ars combinatoria, princípio e procedimento estético que marcaria um segmento de sua produção ficcional nas décadas de 60 e 70. Partindo da imagem de um contador de histórias a outros membros de sua tribo, seu argumento se desenvolve para provar como, desde as narrativas mais fundamentais do discurso oral, às mais elaboradas do registro escrito literário, pode-se observar sempre um modus operandi subjacente: a comutação e a reordenação de elementos finitos e discretos (no sentido matemático do termo), conforme padrões associativos pré-estabelecidos.

O narrador explorava as possibilidades implícitas da própria linguagem, combinando e permutando as figuras, as ações e os objetos sobre os quais essas ações podiam se exercer. Derivavam daí histórias, construções lineares que sempre apresentavam algumas correlações, algumas contraposições: o céu e a terra, a água e o fogo; os animais que voam e aqueles que cavam tocas, cada termo com seu aparato de atributos, seu repertório de ações. (CALVINO, 2009, p. 197)

Ao longo do ensaio, Calvino lança mão de referências a variados escritores de textos literários, filosóficos e teórico-críticos para evidenciar como as propriedades de seleção 
e combinação da Linguística Estrutural presidem não apenas à formação de palavras e frases, senão também de textos, conforme os modelos narratológicos de Propp e Greimas. A lógica permutacional da narrativa, dissecada nos principais escritos do formalista russo e do semioticista lituano, é também objeto de alusões explícitas em outros textos teóricos do ficcionista italiano, como "Leveza" (CALVINO, 2003), "Em memória de Roland Barthes" (CALVINO, 2010) e "Como escrevi um dos meus livros" (CALVINO, 1990), para citar apenas alguns.

Se, em "Cibernética e fantasma", o escritor advoga com base no axioma de que tanto os textos quanto o universo funcionam como uma "série de estados descontínuos, de combinações de impulsos sobre um número finito (um número enorme, mas finito)" (CALVINO, 2009, p. 200), revela-se um desdobramento algo previsível, considerando o desenvolvimento tecnológico de então e os experimentos literários de outros membros do Oulipo à época, a provocação que Calvino lança diante da Computação:

\footnotetext{
Estabelecidos esses procedimentos, e entregue a um computador a tarefa de realizar tais operações [de combinatória], teremos a máquina capaz de substituir o poeta e o escritor? Assim como já temos máquinas que leem, máquinas que executam análises linguísticas de textos literários, máquinas que traduzem, máquinas que resumem, teríamos, então, máquinas capazes de criar e compor poemas e romances? O que interessa nem é tanto se esse problema tem solução prática — porque, afinal, não valeria a pena construir máquina tão complicada -, mas sua viabilidade teórica, que poderia abrir uma série de conjecturas insólitas. (CALVINO, 2009, p. 203, grifos nossos)
}

É interessante pensar que, na década de 60, quando o ensaio em questão foi escrito, Calvino tomava o problema das textualidades automaticamente geradas por máquinas como eminentemente teórico, e não propriamente técnico. No entanto, engajado que sempre esteve na reflexão sobre a escrita como um tabuleiro de peças a serem reordenadas para variadas partidas, defrontou-se muitas vezes ao longo da carreira com as mesmas questões, às quais tentou responder, alguns anos mais tarde, num exercício ficcional, redigindo o conto "O incêndio da casa abominável". Neste, um "programador-analista de sistemas" narra a investigação sobre um conjunto de doze crimes que culminam no incêndio de um palacete, sendo a reconstituição dos delitos - a calcular por meio de um software de responsabilidade do narrador - necessária para fins securitários. Contudo, por ser desconhecida a ordem das doze ações criminosas, bem como suas motivações ou as combinações agressor/vítima entre os quatro personagens envolvidos em cada um dos crimes, toda a narrativa se estrutura como fabulação das possíveis comutações: 
Mesmo admitindo que nenhuma das doze ações tenha sido realizada por só uma pessoa contra só uma outra, reconstituir os acontecimentos é tarefa árdua: se os personagens em questão são quatro, tomados dois a dois podem configurar doze relações diferentes para cada um dos doze tipos de relações listadas. As soluções possíveis são, portanto, doze à décima segunda potência, isto é, tem de se escolher entre um número de soluções que se eleva a oito trilhões, oitocentos e setenta e quatro bilhões, duzentos e noventa e seis milhões, seiscentos e setenta e dois mil, duzentos e cinquenta e seis. (CALVINO, 2001, p. 150)

Ainda que seja óbvia a conexão entre o mote do conto e as perguntas que Calvino lança em "Cibernética e fantasmas" acerca da produção textual automática, não podemos ignorar que "O incêndio da casa abominável" não foi composto por uma máquina. Tratase de texto ficcional escrito por um humano (Calvino), que projeta numa voz narrativa também humana uma série de lucubrações ora realizadas mentalmente pelo "programador-analista de sistemas", ora por ele reportadas a partir dos cálculos de seu computador.

Infelizmente, assim como os personagens mortos no conto em questão, Italo Calvino faleceu antes de poder ver operações narrativas de combinatória sendo efetuadas sistematicamente por computadores. Na segunda década do século XXI, estas se tornaram bem mais frequentes no universo das poéticas de vanguarda com as novas mídias, a exemplo do romance generativo If on a Winter's Night a Library Cardholder, de Robin Camille Davis, desenvolvido na edição de 2016 do NaNoGenMo - National Novel Generation Month (em português, "mês nacional de geração de romance”).

Como a tradução do nome sugere, o NaNoGenMo é uma espécie de iniciativa para fomentar o desenvolvimento de romances gerados por computadores ${ }^{3}$ entre interessados em arte e tecnologia, os quais trocam, através da plataforma GitHub, ideias, experiências e códigos de programação usados na feitura das obras. Consoante informações disponíveis no site do NaNoGenMo (n.d.), sua primeira realização foi em 2013, repetindo-se a cada mês de novembro até hoje, de maneira análoga ao que se pratica no

\footnotetext{
${ }^{3}$ De modo geral, projetos de tal natureza operam de maneira algo similar: partem de templates com uma matriz sintática que determina a estrutura geral dos textos a serem gerados, ao passo que os elementos que preenchem as "variáveis" da matriz são selecionados, no eixo paradigmático, a partir de um universo finito de possibilidades, cadastradas em bancos de dados. A diversidade dos resultados reside nos modos como a matriz é composta, na constituição do repositório cujos termos são permutados e nas formas como a interface apresenta os resultados ao leitor, podendo, ou não, permitir que este intervenha no processo gerativo. Para mais informações, cf. Barbosa (2001a).
} 
movimento NaNoWriMo - National Novel Writing Month (em português, "mês nacional de escrita de romance") desde 1999.

Tanto no NaNoGenMo quanto no NaNoWriMo, a única regra a ser seguida é a do número mínimo de palavras do romance: cinquenta mil. Contudo, no caso de textos gerados por máquinas, visto que há muitas formas de articular algoritmos e bancos de dados para, automaticamente, atingir essa cifra, os organizadores do NaNoGenMo acharam por bem explicitar na página oficial: “ $\mathrm{O}$ 'romance’ é definido como você quiser. Podem ser 50.000 repetições da palavra 'miau'. Pode simplesmente pegar um romance aleatório do Projeto Gutenberg. Não faz diferença, contanto que tenha mais de 50k palavras"4 (NaNoGenMo, n.d., n.p., tradução nossa).

Resta patente, nessa definição, o caráter conceitual esperado nas obras geradas por uma máquina, em que as ações de recortar, copiar, colar e repetir ganham proeminência frente à originalidade da narrativa, à fluidez de um pretenso enredo ou à imersão no universo ficcional, numa dinâmica de remixagem literária que Kenneth Goldsmith (2011) chamou de "escrita não criativa", e Marjorie Perloff (2012) associa ao "gênio não original", tendências radicalizadas nos experimentos de literatura eletrônica.

Por conseguinte, os resultados das criações automáticas do NaNoGenMo acabam por se aproximar mais dos formalismos mais radicais de Queneau do que dos romances e contos de Calvino, em que a regularidade da permutação matemática vem sempre acompanhada de uma surpreendente elaboração da fábula. A esse respeito, o próprio autor italiano afirmara, na conferência "Exatidão", em Seis propostas para o novo milênio, que via o sistemático e o errático como contrafaces de um mesmo fenômeno: “de um lado o cristal (imagem de invariância e de regularidade das estruturas específicas), e de outro a chama (imagem da constância de uma forma global exterior, apesar da incessante agitação interna)" (CALVINO, 2003, p. 84).

De volta ao romance generativo If on a Winter's Night a Library Cardholder, cumpre ressaltar que é também flertando com a exatidão e a imprevisibilidade que Robin Camille Davis descreve seu trabalho na aba README.md (DAVIS, 2018b) de sua conta no

\footnotetext{
${ }^{4}$ Trecho original: "The 'novel' is defined however you want. It could be 50,000 repetitions of the word 'meow'. It could literally grab a random novel from Project Gutenberg. It doesn't matter, as long as it's $50 \mathrm{k}+$ words".
} 
Github. Nesse paratexto, intitulado conforme os protocolos mais comuns de documentação de programação, a autora refere-se a seu projeto ora como narrativa (para a qual apresenta uma sinopse), ora como código computacional, descrito na aba Appendices (DAVIS, 2018a).

A seguinte síntese do enredo de If on a Winter's Night a Library Cardholder é apresentada aos leitores por Davis:

Você, o protagonista, meio que se lembra de um livro que leu há muito tempo e quer ler de novo - mas não consegue se lembrar do título. Você visita cada uma das 216 filiais de biblioteca na cidade de Nova Iorque procurando por ele. Em cada biblioteca, você encontra um livro que parece familiar e lê uma página... É esse o livro que você vem tentando encontrar? ${ }^{5}$ (DAVIS, 2018b, n.p., tradução nossa).

Na sinopse acima, logo notamos outras semelhanças com Se um viajante numa noite de inverno, para além do manifesto decalque entre os títulos. No plano do conteúdo, destacase a isotopia referente a livros, leitura e biblioteca, tornada ainda mais significativa ao sabermos que Davis é, ela mesma, bibliotecária. Em termos de sintaxe narrativa, há também replicação da macroestrutura do texto calviniano, que se desenrola alternando o relato (encaixante) de uma busca e os excertos (encaixados) lidos pelos protagonistas durante esse percurso. Por fim, no que tange à dêixis e à enunciação, tal qual no romance de Calvino, o protagonista da história gerada pela máquina é instanciado como um "você, leitor", e não como primeira ou terceira pessoa discursiva.

Por outro lado, segundo se lê também no paratexto README.md, as semelhanças param por aí. Afinal, If on a Winter's Night a Library Cardholder é um texto produzido por uma sequência de procedimentos de seleção aleatória de elementos numa base de dados, ao passo que Se um viajante numa noite de inverno tem como eixo estruturante uma série intencional de homologias entre a errância do protagonista e os dez incipits que ele lê. $\mathrm{O}$ encaixamento perfeito entre distintos níveis diegéticos no romance de Calvino salienta a cuidadosa arquitetura romanesca metaliterária do autor e sua busca constante pelo exato (CALVINO, 2003), mas sem que para isso se tornasse refém do randômico.

\footnotetext{
${ }^{5}$ Trecho original: "You, the protagonist, half-remember a book you read long ago and want to read again — but you can't remember the title. You visit each of the 216 library branches in New York City looking for it. At each library, you find a book that looks familiar and you read a page... Is this the book you've been trying to find?"
} 
Como consequência dos diferentes procedimentos de criação (com aleatoriedade no projeto de Davis e intencionalidade no de Calvino), há um segundo nível em que ambas as obras divergem radicalmente. Se um viajante numa noite de inverno é uma narrativa que permite variadas rotas de leitura e interpretações, como hipertexto que é, muito embora escrito antes da popularização das tecnologias digitais de informação e comunicação. É, portanto, uma obra múltipla do ponto de vista hermenêutico, mas inalterável como códice em cujas páginas o texto impresso não se abre à edição pelo leitor. Por sua vez, If on a Winter's Night a Library Cardholder é uma obra sempre diferente de si mesma, dado que, a cada vez que o código de programação é executado, um novo romance é gerado, recombinando de maneira inaudita informações armazenadas em bancos de dados. A propósito, ressalte-se que, diante das tantas variações que um texto combinatório pode assumir, todas as vezes em que neste artigo nos referirmos à imanência do romance generativo, tomamos por base a versão apresentada por Davis (2016) no NaNoGenMo daquele ano e disponível no GitHub. Desnecessário é dizer que recombinações distintas implicariam análises também distintas - desafio metodológico a que estão sempre submetidas as pesquisas sobre literatura eletrônica.

Ainda no paratexto README.md, encontramos uma especulação sobre a estúpida quantidade de variações que a máquina poderia produzir: "Creio que há $4.5 \times 10^{1366}$ romances que podem ser gerados por este script. Para fins de comparação, estima-se que existem $10^{82}$ átomos no universo"6 (DAVIS, 2018b, n.p., tradução nossa). Numa obra maior que o universo (paradoxo bem ao gosto de Calvino e seus experimentos incompossíveis com a ficção e a ciência), a textualidade se desenvolve segundo processos iterativos (como o cristal), mas aleatórios (como a chama), cruzando as bases do NYC Open Data, de onde extrai dados sobre as bibliotecas da cidade de Nova Iorque, e do Projeto Gutenberg, do qual puxa, randomicamente, passagens de mais de sessenta mil livros em domínio público. De posse de metadados de qualquer biblioteca e de qualquer livro nessas duas bases, o programa preenche aleatoriamente uma matriz de baixa variabilidade, como a que se transcreve abaixo.

Você chega a [79-50 Bell Boulevard], [Bayside] e se vê nos degraus da [Windsor Park Library]. // Enquanto procura nas pilhas, algo pesado cai de repente sobre sua cabeça. 'Ai!' você grita. Mas não há ninguém, por perto.

\footnotetext{
${ }^{6}$ Trecho original: "I believe that there are $4.5 \times 10^{1366}$ possible novels that can be generated by this script. For comparison, there are an estimated $10^{82}$ atoms in the universe".
} 
Você esfrega seu crânio e olha para o livro de capa de tecido vermelha que caiu sobre você. ['Two Wyoming Girls and Their Homestead Claim: A Story for Girls,'] você murmura. Talvez isso seja um sinal. // Você abre numa página aleatória e começa a ler... // [... Apenas pense, nós estamos neste lugar há cerca de cinco anos, e nunca conseguimos colher nada, porque o gado do $\mathrm{Sr}$. Horton, não importa onde esteja pastando, sempre chega bem na hora - na hora exata - de causar o máximo de estrago. $O$ gado dos outros vizinhos mal invade nossos campos, e quando o faz os vizinhos reagem bem. Pense no tempo quando o rebanho de Mr. Rollin entrou no milharal e comeu todas as fileiras de milho, uma atrás da outra. Mr. Rollins foi ele mesmo atrás deles e pagou pelo estrago, sem reclamar. Além disso, ele disse que não aconteceria de novo; e não aconteceu. Quando Mr. Horton fez algo assim?" "Ele tem estado ocupado de outras formas," papai disse, e sua voz não tem nada do ressentimento que a de Jessie expressava. ...] // Não, este não é o livro que você tinha em mente, muito embora ele o deixe intrigado. Você considera levá-lo, mas não tem muito tempo antes de a próxima biblioteca fechar. Você sai e direciona seus pés para a próxima biblioteca na sua lista. ${ }^{7}$ (DAVIS, 2016, n.p., tradução nossa).

Esta mesma cena se repete com pequenas variações 215 vezes na narrativa, uma imediatamente atrás da outra, o que representa na interface, por expedientes verbais, os ciclos iterativos do processamento dos dados. Os diferentes recursos tipográficos, na transcrição acima, têm por fim identificar como cada uma das partes dessa cena é composta por uma dinâmica distinta, o que garante a variabilidade nos blocos textuais produzidos de maneira encadeada pelo código de programação. Em negrito, estão os trechos que permanecem exatamente idênticos em todas as 215 reiterações; entre colchetes, dados que são recuperados aleatoriamente dos bancos de dados do NYC Open Data (o endereço e o nome de uma biblioteca) e do Projeto Gutenberg (o título e o trecho de um livro), variando a cada novo ciclo. Já em sublinhado, temos trechos que são parafraseados a cada nova iteração, mas relatando a mesma cadeia de eventos: que o

\footnotetext{
${ }^{7}$ Texto original: "You arrive at [79-50 Bell Boulevard], [Bayside], and find yourself on the steps of [Windsor Park Library]. // While browsing the stacks, something heavy suddenly falls onto your head. 'Ouch!' you shout. But no one is nearby. You rub your cranium and look at the red cloth-covered book that fell on you. ['Two Wyoming Girls and Their Homestead Claim: A Story for Girls,'] you mutter. Perhaps this was a sign. // You flip to a random page and begin to read... // [... Only think, we've been on this place nearly five years, and we've never yet raised a crop, because Mr. Horton's cattle, no matter where they may be ranging, always get up here just in time--the right time--to do the most damage. The other neighbors' cattle hardly ever stray into our fields, and when they do the neighbors are good about it. Think of the time when Mr. Rollins's herd got into the corn field and ate the corn rows down, one after another. Mr. Rollins came after them himself, and paid the damage, without a word of complaint. Besides, he said that it shouldn't happen again; and it didn't. When has Mr. Horton ever done a thing like that?" "He's been kept busy other ways," father said, and his voice had none of the resentment that Jessie's expressed. ...] // No, this isn't the book you had in mind, although it does intrigue you. You consider checking it out, but you don't have much time before the next branch closes. You go outside and point your feet toward the next branch on your list."
} 
protagonista encontrou um códice na biblioteca, folheou-o, descobriu não se tratar do livro que procurava e partiu para a próxima biblioteca, apenas para reiniciar o loop narrativo.

Se na capacidade dos computadores de executar rapidamente funções em série reside o truque da geração automática do romance, a mesma circularidade acaba por tornar a leitura do texto algo enfadonha. Após algumas linhas, o leitor logo se enfara do jogo de reconhecimento de padrões na matriz generativa e dificilmente acompanha até o fim a busca do protagonista pelo livro perdido. Nesse caso, pode ser que opte por descer a barra de rolagem até o final, a fim de conhecer o desfecho da história, e encontre tão-somente uma breve alteração nas últimas frases da $216^{\mathrm{a} 8}$ cena: "Você ri consigo mesmo. Sim, esse livro, esse é o livro. Você caminha para o balcão de empréstimos às 4:59 da tarde, quase na hora de a biblioteca fechar. No trem de volta para o seu apartamento, você abre na página 1. Esta vai ser uma noite muito boa"” (DAVIS, 2016, n.p., tradução nossa).

Tem-se aqui um encerramento diegético bastante tradicional, em que o protagonista encontra, no último minuto disponível, o objeto há muito buscado, e a isso se soma um segundo tropo romanesco, também deveras desgastado: a história se conclui com o protagonista lendo um livro. Curioso, porém, é pensar que o excerto final de If on a Winter's Night a Library Cardholder, parecido com tantos outros romances e contos com as mesmas soluções narrativas, é justamente o único “original” da obra criada por Davis, no sentido de ter sido redigido pela autora, e não gerado pela máquina. Ao fim e ao cabo, defrontamo-nos com um dos paradoxos fundantes do pós-estruturalismo francês: tanto o segmento "original” quanto as 215 repetições automáticas que o precedem são igualmente secundários ou derivados: trata-se sempre de operações de combinatória verbal, processadas pela mente humana ou pelo computador.

\footnotetext{
${ }^{8}$ Note-se que, diferente das 215 cenas anteriores, nesta última não nos é permitido ver o conteúdo do livro lido pelo protagonista. Desse modo, embora haja 216 bibliotecas visitadas no enredo, o romance generativo transcreve aleatoriamente apenas 215 fragmentos de livros da base do Projeto Gutenberg, o que justifica que em algumas análises quantitativas, na terceira seção deste artigo, ora lancemos mão de um valor, ora de outro, a depender do tipo de dado a ser quantificado.

${ }^{9}$ Trecho original: "You smile to yourself. Yes, this book, this is the book. You walk to the checkout desk at 4:59pm, just before the library closes. On the train back to your apartment, you open to page 1. It's going to be a very good night".
} 
Ademais, ainda sobre o desfecho narrativo, cumpre ressaltar aqui uma interessante distinção entre os procedimentos autorreflexivos de closure em Se um viajante numa noite de inverno e If on a Winter's Night a Library Cardholder. Na última cena do romance de Calvino, o protagonista lê um livro que tem por título "Se um viajante numa noite de inverno" e foi escrito por um personagem chamado Italo Calvino. Logo, a busca desse protagonista por um livro, ao longo de toda a história, redunda no próprio livro dentro do qual ele existe, num movimento de circularidade perfeita. Já em If on a Winter's Night a Library Cardholder, o livro que o protagonista lê na derradeira cena não se chama If on a Winter's Night a Library Cardholder. O códice que o personagem finalmente encontra, na última cena, é mais um dos títulos aleatoriamente selecionados na base do Projeto Gutenberg; logo, varia para cada uma das versões do romance de Davis. Nesse caso, mais do que uma homologia entre o texto que lemos e o que o protagonista acaba por ler, a estrutura de If on a Winter's Night a Library Cardholder evidencia uma seriação sem o espelhamento totalizante entre os títulos do romance e do códice finalmente encontrado pelo protagonista.

\section{(Re)combinando para ler de longe}

$\mathrm{Na}$ seção anterior do presente artigo, realizamos um exercício hermenêutico de If on a Winter's Night a Library Cardholder segundo procedimentos que se canonizaram nos Estudos Literários sob o nome de close reading, analisando "de perto" algumas porções do romance gerado por Davis a fim de discuti-las à luz de ideias sobre literatura, combinatória e tecnologia constantes em ensaios de Calvino. Tal abordagem teóricometodológica foi útil para descrever o funcionamento da obra e perceber sentidos imanentes a alguns segmentos específicos de sua textualidade, em confronto com o contexto experimental da literatura combinatória eletrônica e com intertextos calvinianos.

No entanto, talvez a análise de uma obra produzida por expedientes tão distintos possa se beneficiar de modos também outros de leitura, nos quais o computador seja mobilizado como máquina semiótica (BARBOSA, 2001a) também para a atividade interpretativa. Nesse sentido, seguindo a ideia de Alan Turing (apud QUENEAU, 1961, n.p., tradução nossa) de que "apenas uma máquina pode apreciar um soneto escrito por uma outra máquina"10, procedemos a algumas operações de distant reading (MORETTI, 2013) de

\footnotetext{
${ }^{10}$ Trecho original: "Seule une machine peut apprécier un sonnet écrit par une autre machine".
} 
If on a Winter's Night a Library Cardholder, em comparação ao romance de Calvino, por intermédio de recursos digitais para processamento de texto, conforme detalhado mais à frente.

Franco Moretti e seu grupo de pesquisa vêm nos últimos anos defendendo uma abordagem nos Estudos Literários que, por um lado, amplia o corpus de pesquisas na área para muito além do cânone e, por outro, advoga pelo uso de metodologias caras às humanidades digitais para coletar, visualizar e analisar dados que se tornam quantitativamente muito vastos e impraticáveis para fins de close reading quando consideramos os polissistemas literários externos às historiografias tradicionais. O título de seu livro, Graphs, Maps, Trees: Abstract Models for a Literary History (MORETTI, 2007), já nos sugere alguns dos formatos como tais dados podem ser organizados para construir sentidos acerca de variadas frentes do sistema literário e mesmo da textualidade de obras cuja manipulação interpretativa ganhas novas possibilidades quando apoiada por tecnologias digitais.

No caso de If on a Winter's Night a Library Cardholder, temos, pois, muitas justificativas para uma análise que considere também recursos de distant reading. Trata-se, afinal, de obra externa ao cânone, mas que com ele dialoga de perto enquanto releitura de Calvino. Além disso, seu texto se produz por procedimentos combinatórios computacionais envolvendo cifras muito altas. Por fim, como mencionado anteriormente, a automática repetição 215 vezes da mesma cena, com pouca variação, acaba por enfarar qualquer leitor e convidar a uma leitura "de longe" da obra, a fim de entrever alguns de seus padrões, e não tanto a uma exaustiva crítica de suas minúcias.

Neste exercício de distant reading, optamos pela utilização de uma aplicação web de análise textual quantitativa, a Voyant Tools (SICLAIR; ROCKWELL, 2020), considerando sua interface amigável para não especialistas em Estatística (perfil comum na área de Letras), a praticidade no seu manuseio e a sua gratuidade. Em seguida, procedemos a uma seleção de três corpora a serem analisados. O primeiro foi composto por dois arquivos: um com o texto integral de Se um viajante numa noite de inverno e outro com o de If on a Winter's Night a Library Cardholder. O segundo corpus era integrado por dez arquivos, cada um contendo um dos incipits lidos pelo protagonista de Se um viajante numa noite de inverno. O terceiro era composto por 215 arquivos, cada 
um contendo um dos excertos de livros lidos pelo protagonista de If on a Winter's Night a Library Cardholder. Tal organização tinha por fim permitir comparações entre as estruturas do livro de Calvino e do romance generativo de Davis, bem como os cotejos entre as narrativas encaixantes e as leituras encaixadas.

Após a definição dos corpora, "limpamo-los" de elementos que distorceriam os resultados da análise automática, como erros de digitalização, números de página, cabeçalhos etc. Em seguida, fizemos upload dos arquivos na aplicação web Voyant Tools e buscamos, entre as ferramentas analíticas disponíveis no sistema, aquelas que mais contribuiriam para a discussão empreendida no presente artigo.

No que tange às relações quantitativas entre If on a Winter's Night a Library Cardholder e Se um viajante numa noite de inverno ${ }^{11}$, destacamos de início a diferença no total de palavras de cada um desses textos, calculada por intermédio da ferramenta Summary na aplicação Voyant Tools: o de Davis tem 53.748; o de Calvino, 82.172. Ainda que pareçam números arbitrários, estes se tornam significativos quando pensamos que o romance generativo é consideravelmente menor que o do ficcionista italiano, conquanto sua extensão não seja definida pela inventividade da autora, ou em decorrência de questões de estilo. Sendo um texto gerado automaticamente pela permuta de elementos em uma mesma cena várias vezes repetida, o "trabalho" de desenvolvimento de código para fabricar uma narrativa de $1.000,1.000 .000$ ou 1.000.000.000 de palavras é praticamente o mesmo. A escolha de Davis é condicionada apenas pelo limite mínimo de palavras determinado no NaNoGenMo (50.000) e pela restrição quantitativa que organiza seu enredo: 216 visitas a espaços diferentes em busca de um livro, uma para cada biblioteca existente na cidade de Nova Iorque.

Também merece atenção a diferença na extensão média dos excertos encaixados em ambas as obras, as quais alternam segmentos relatando a busca dos protagonistas e segmentos transcrevendo os textos lidos por essas personagens. Ao passo que os incipits encaixados no romance de Calvino são num total de dez, com uma média de 3.621,3 palavras cada, o romance gerado automaticamente nos apresenta um total de 215 trechos de livros lidos pelo protagonista em sua busca, com uma extensão média de 133,27

${ }^{11}$ Para que a comparação automática entre os textos fosse possível, optamos por, na etapa de distant reading, trabalhar com uma tradução em língua inglesa do romance de Calvino (1981), a fim de que o idioma fosse o mesmo do projeto de Davis. 
palavras cada. Entre outras hipóteses analíticas, podemos pensar a radical diferença nos quantitativos médios de palavras como uma contingência dos enredos: afinal, em Se um viajante numa noite de inverno, temos um arco temporal bastante amplo, o que daria condições aos protagonistas de lerem textos mais longos; contudo, em If on a Winter's Night a Library Cardholder, toda a busca pelo livro perdido transcorre entre 4:00 e 4:59 da tarde de um mesmo dia. A despeito da inverossimilhança de uma peregrinação por 216 bibliotecas em Nova Iorque em menos de uma hora, um enredo desta natureza não poderia permitir ao protagonista ler muito mais que um punhado de palavras em cada livro encontrado.

É assente na fortuna crítica sobre Calvino que os incipits lidos pelo protagonista de Se um viajante numa noite de inverno também poderiam figurar como contos autônomos interrompidos próximos ao clímax. Meio aos moldes de As mil e uma noites, vai o leitor do romance italiano acompanhando esse movimento cadenciado de inícios e suspensões das narrativas encaixadas, num processo determinado pela macroestrutura do metarromance de Calvino e pela microestrutura de cada um dos incipits.

Outro, porém, é o modus operandi de If on a Winter's Night a Library Cardholder, cujos fragmentos de textos encaixados são muito mais breves e se constituem como partes aleatórias de obras cadastradas na base do Projeto Gutenberg. Desse modo, não podem ter existência independente, sendo destituídos de qualquer estrutura de closure quanto a um começo, meio e fim discursivos. Casos há, inclusive, em que tais fragmentos revelam incompletudes mais fundamentais, transpondo pedaços de sentenças dos livros "originais" sem preocupação sequer com a autossuficiência sintática ou tipográfica dos excertos, que podem, por exemplo, ser copiados faltando uma oração principal, ou mesmo com um parêntese de abertura amputado de seu complementar de fechamento.

A arbitrariedade nos recortes de outras obras a figurar no romance generativo, em comparação à intencionalidade que preside aos incipits de Calvino, torna-se ainda mais evidente se cotejarmos a variação de tamanho dos excertos mais longo e mais curto de cada série com a extensão média dos demais elementos. No romance de Calvino, o incipit mais longo e o mais curto, respectivamente com 4.909 e 2.449 palavras, afastam-se proporcionalmente pouco da média de 3.621,3 termos, garantindo relativo isomorfismo entre as partes do romance. Já os excertos encaixados em If on a Winter's Night a Library 
Cardholder são bem mais discrepantes: o maior deles tem 182 palavras, enquanto outros só apresentam um sinal de reticências, sem qualquer palavra que as acompanhe.

Casos como este, de excertos sem qualquer palavra, possivelmente se devem a erros no processo generativo automático, os quais, num plano estritamente matemático, elevam ao infinito a taxa de variação entre 0 e a extensão média de 133,27 termos. Contudo, a questão pode ir mais além: a manutenção de tais falhas na versão do romance apresentada por Davis ao final do NaNoGenMo indica, no mínimo, falhas no processo de revisão do texto pela autora, ou, na pior das hipóteses, que nem mesmo ela entende sua obra como um romance a ser lido "de perto" a fim de evitar potenciais gralhas. Eis-nos, pois, de volta à ideia Turing, de que um texto escrito por uma máquina há de ser devidamente apreciado apenas por outra máquina.

Aprofundando um pouco mais as operações de distant reading para contrastar a natureza dos textos lidos pelos protagonistas de Calvino e Davis, podemos também analisar quantitativamente a frequência lexical em cada uma das séries. Nas Figuras 1 e 2, referentes a Se um viajante numa noite de inverno e If on a Winter's Night a Library Cardholder, respectivamente, observamos nuvens de palavras em que, quanto mais perto do centro da imagem e quanto maiores as letras, mais frequentes são os vocábulos no corpus. Ambas as imagens foram geradas usando a ferramenta Cirrus da aplicação Voyant Tools.

Figuras 1 e 2 - Nuvens de palavras dos excertos encaixados em Se um viajante numa noite de inverno e If on a Winter's Night a Library Cardholder
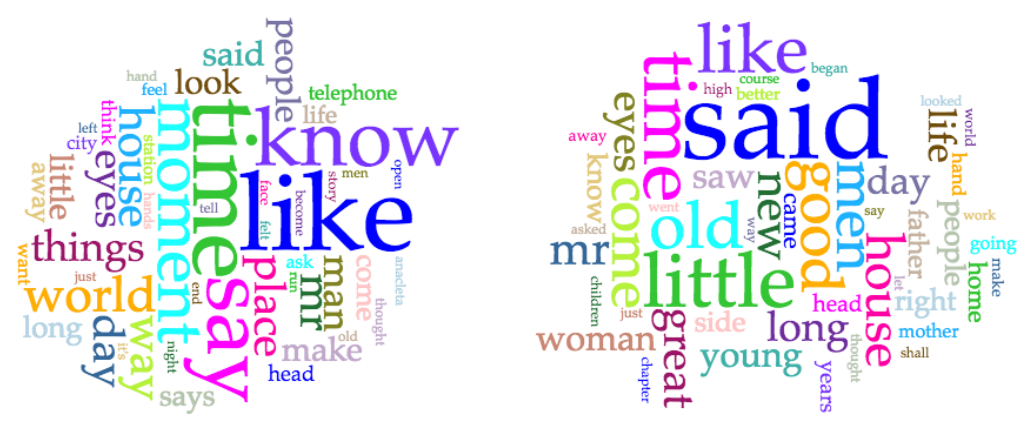

Fonte: elaboração pelo autor com a aplicação Voyant Tools (SICLAIR; ROCKWELL, 2020)

A mais evidente (e desconcertante) constatação depreendida do cotejo das imagens é a relativa semelhança entre elas. Muito embora a Figura 1 se refira a incipits 
intencionalmente redigidos por Calvino e a Figura 2 a excertos aleatoriamente transcritos do banco de dados do Projeto Gutenberg, muitos dos termos mais comuns são os mesmos em ambos os contextos, como like, say(s)/said, time, mr, house, people, head, know, come, long etc. Apesar das óbvias diferenças entre os procedimentos de criação das obras, a similitude vocabular nesses excertos nos lembra, mais uma vez, que todo texto, literário ou não, feito por humanos, máquinas ou ensembles ciborgues, mais não é que recombinação dos signos de uma língua - um banco de dados lexical, afinal ${ }^{12}$. A esse respeito, é iluminadora outra asserção de Calvino (2009, p. 124), em "Cibernética e fantasmas", ressaltando que as possibilidades do texto literário estão, desde sempre, codificadas já como possibilidades no seio da linguagem: "mesmo que entregue à máquina, a literatura continuará sendo um lugar privilegiado da consciência humana, uma explicitação das potencialidades contidas no sistema de signos de toda sociedade e de toda época".

Se a análise dos itens mais frequentes (em termos absolutos) em cada série de textos encaixados nas narrativas de Calvino e Davis pouco nos diz sobre as especificidades de cada obra, outros recursos de visualização na aplicação Voyant Tools podem nos permitir mais insights, quando da análise de palavras específicas em seus co-textos. Partindo de tal premissa, optamos por fazer um movimento de leitura reverso: em vez de analisar como os fragmentos encaixados afetam o enredo das narrativas encaixantes de $\mathrm{Se} \mathrm{um}$ viajante numa noite de inverno e If on a Winter's Night a Library Cardholder, interessanos agora pensar as relações que determinadas palavras nas narrativas encaixantes adquirem, intencional ou aleatoriamente, quando repetidas nos excertos encaixados. Sob essa lógica, interessou-nos verificar como as palavras book e read (e potenciais flexões e cognatos iniciados pelas mesmas letras, como books, bookshelves, reads, reading, reader

\footnotetext{
${ }^{12}$ A dinâmica combinatorial que preside ao funcionamento de uma língua garante padrão razoavelmente estável em diferentes corpora, sobretudo no que tange às palavras mais frequentes. No COCA - Corpus of Contemporary American English (DAVIES, 2008), maior corpus online gratuito de textos no inglês contemporâneo, com mais de um bilhão de palavras cadastradas, também estão listadas entre as mais cem frequentes algumas das que constam nas nuvens das Figuras 1 e 2, como say, come, people, know, like e time. Note-se, porém, que tal constatação não invalida a análise proposta neste artigo; a bem da verdade, reforça o argumento sobre o caráter combinatorial das línguas subjacente aos projetos estéticos de Calvino e Davis.
} 
etc., subsumidas pela codificação book* e read $^{* 13}$ ) funcionam nos textos lidos pelos protagonistas dos romances de Calvino e Davis.

Usando a ferramenta Terms, temos acesso aos quantitativos desses termos para cada um dos corpora. Nos incipits de Calvino, book* tem 8 ocorrências e read* tem 36, num universo de 36.213 palavras, o que nos leva a uma razão de 0,00121503; nos excertos de livros do Projeto Gutenberg, encaixados no romance de Davis, book* tem 12 ocorrências e read* tem 17, num universo de 28.654 palavras, equivalendo a uma razão de 0,00101208. Se trabalharmos com aproximações de apenas três casas decimais, perceberemos que os valores são muito próximos, sugerindo um movimento quantitativo semelhante no que tange a essas duas strings de busca. Assumindo que o tratamento de questões relativas a livros e leituras, nesses fragmentos encaixados, gera uma inflexão metanarrativa, a despeito da intencionalidade do autor ou da aleatoriedade do processo generativo que culminou na presença dessas palavras, podemos dizer que, em termos estritamente numéricos, o cariz autorreflexivo se assemelha entre os textos de Calvino e Davis.

Caso queiramos ir mais além, podemos também utilizar outra ferramenta Voyant Tools, como Links, que representa graficamente como uma rede as relações entre uma palavra e outras em sua vizinhança. Neste exercício analítico, considerando tratar-se, em última medida, de romances sobre a busca de um livro, optamos por gerar a rede formada pelo termo-chave $b_{o o k}{ }^{*}$ e as dez palavras mais frequentes em sua vizinhança - aqui definida com abrangência de cinco termos antecedendo ou sucedendo o termo-chave. As Figuras 3 e 4 representam, respectivamente, os resultados obtidos com os corpora dos textos encaixados em Se um viajante numa noite de inverno e If on a Winter's Night a Library Cardholder.

\footnotetext{
${ }^{13}$ Dadas as contingências da língua inglesa, eliminamos manualmente as ocorrências da palavra ready (em português, "pronto"), que também se inicia por read, mas não guarda semelhanças morfológicas ou semânticas, num corte sincrônico, com a base read.
} 
Figuras 3 e 4 - Redes de palavras co-ocorrentes com book* em Se um viajante numa noite de inverno e If on a Winter's Night a Library Cardholder
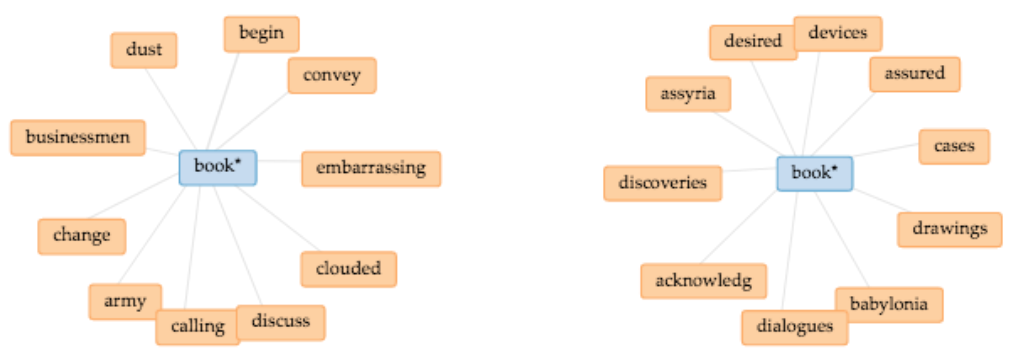

Fonte: elaboração pelo autor com a aplicação Voyant Tools (SICLAIR; ROCKWELL, 2020)

Nas conexões estabelecidas entre book* e sua vizinhança nos incipits de Calvino (Figura 3), notamos a predominância de alguns campos semânticos, como os do turvamento (em dust/"poeira" e clouded/"nebuloso"), da comunicação (em convey/ "transmitir", discuss/“discutir", calling/“chamando”) e dos processos (em begin/“começar” e change/“mudar"). Na interseção desses campos, notamos como, nas narrativas lidas pelo protagonista, replicam-se temas caros ao enredo principal do romance, em que o processo de busca por um livro específico é continuamente atravessado por mal-entendidos.

A seu turno, quando analisamos na Figura 4 a rede entre $b_{o o k}$ e sua vizinhança nos excertos aleatoriamente incorporados ao romance generativo de Davis, entrevemos relações diferentes. Ainda que também tenhamos o campo semântico da comunicação (em drawings/“desenhos” e dialogues/“diálogos”), esta não se associa mais ao dinâmico, como na Figura 3, e sim a imagens locativas estáticas (em babylonia/"Babilônia" e assyria/“Assíria"). Muito embora se trate do resultado de uma combinação randômica de elementos, é interessante pensar que, nesses trechos do romance digital, a forma book* evoca mais conexões com termos indicativos de imobilismo do que seu correspondente no livro impresso de Calvino, o que subverte o imaginário popular em torno do computador e do códice.

A reforçar tal hipótese exegética, em que sentidos construídos aleatoriamente pelo romance generativo nos fazem repensar os modos como são compostas e lidas as histórias na contemporaneidade, temos ainda outra dobra nesse complexo gesto autorreflexivo. Afinal, contemplando mais atentamente as associações de book ${ }^{*}$ nos excertos automaticamente transcritos da base do Projeto Gutenberg para o romance de Davis, podemos entrever um terceiro campo semântico: o do desenvolvimento técnico (em 
discoveries/“descobertas” e devices/“dispositivos”). Sob tal diapasão, babylonia e drawings nos remetem a suportes eminentemente físicos, mas discoveries e devices abrem a possibilidade para outras formas que um livro possa tomar nos dias de hoje, mesmo que como dados automaticamente recombinados por um sistema. É também nesse interregno entre o impresso e o digital, caro à ficção de Italo Calvino e ao Projeto Gutenberg, que Camille Robin Davis desenvolveu, sob proposta diferente, If on a Winter's Night a Library Cardholder, projeto experimental que aqui lemos ora de perto, ora de longe, com vistas a construir possíveis percursos interpretativos para um romance gerado por um script de programação, mas que trata de uma busca incessante por um códice.

\section{Considerações finais}

Encaminhando-nos para o final da discussão desenvolvida até aqui, retomamos uma postulação de Calvino de 1967, quando o autor previa uma então futura literatura a ser produzida por computadores: “(...) os linguistas passaram a raciocinar em termos de códigos e mensagens, procurando estabelecer a entropia da linguagem em todos os níveis, inclusive o literário. O homem está começando a entender como se desmonta e como se torna a montar a mais complicada e imprevisível de todas as suas máquinas: a linguagem" (CALVINO, 2009, p. 121).

Partindo de algumas formulações de Calvino sobre o tema, tão caro à sua produção ensaística e ficcional, realizamos no presente artigo uma análise de If on a Winter's Night a Library Cardholder, romance generativo desenvolvido por Robin Camille Davis. Para tanto, tomamos por base que a proposta de Davis envolvia uma releitura computacional do mote de Se um viajante numa noite de inverno, o que justificava nosso movimento num vetor contrário, em que as teorias de Calvino nos permitissem uma aproximação da obra apresentada na edição de 2016 do NaNoGenMo - National Novel Generation Month. Sob tal premissa, discutimos como algoritmos de combinatória e bancos de dados distintos (do NYC Open Data e do Projeto Gutenberg) são mobilizados pelo sistema para constituir uma matriz replicada 215 vezes, combinando dinâmicas de repetição e diferença, as quais analisamos na imanência de uma das cenas geradas aleatoriamente.

Na sequência, procedemos a um exercício de distant reading de Se um viajante numa noite de inverno e If on a Winter's Night a Library Cardholder, com vistas a entrever, com recurso a ferramentas computacionais de análise textual, padrões verbais em ambas 
as obras. Utilizando a aplicação web Voyant Tools, investigamos números absolutos e relativos de palavras, bem como as relações que algumas delas contraem com as demais nos corpora, sobretudo termos do campo lexical do livro e da leitura, central nos projetos de Calvino e Davis.

Sabemos, claro está, das limitações impostas pelos métodos adotados para a análise de If on a Winter's Night a Library Cardholder: o close reading de uma cena específica para depreender a matriz combinatória subjacente e o distant reading da obra em confronto com outra por intermédio de um software. No entanto, dadas as proporções do texto de Davis, bem como sua estrutura altamente repetitiva - para não dizer tediosa -, nossa proposta era aqui mesmo não a leitura exaustiva do romance generativo, senão sua abordagem por percursos analíticos menos tradicionais. Talvez seja esta, inclusive, a maior contribuição deste artigo, indicando possíveis caminhos para o estudo acadêmico de obras de tal cariz: se são produzidas automaticamente por sistemas, pode ser que também sejam lidas com mais proveito por sistemas automáticos, cujo output sintético este sim - possa ser lido por humanos. Há que se aproveitar melhor o tempo humano para ler de facto os romances escritos por outros humanos, a exemplo do brilhante Se um viajante numa noite de inverno.

\section{REFERÊNCIAS}

BARBOSA, Pedro. O computador como máquina semiótica.Revista de Comunicação \& Linguagens, Lisboa, n. 29, 2001a. Disponível em: www.pedrobarbosa.net. Acesso em: 02 ago. 2020.

BARBOSA, Pedro. O motor textual. Porto: Edições Universidade Fernando Pessoa, $2001 b$.

CALVINO, Italo. Cibernética e fantasmas: notas sobre a narrativa como processo combinatório. In: CALVINO, Italo. Assunto encerrado: discursos sobre literatura e sociedade. São Paulo: Companhia das Letras, 2009.

CALVINO, Italo. Coleção de areia. São Paulo: Companhia das Letras, 2010. 
CALVINO, Italo. Comment j'ai écrit un de mes livres. In: OULIPO. La Bibliothèque Oulipienne. Paris: Ramsay/Seghers, 1990.

CALVINO, Italo. If on a Winter's Night a Traveler. Tradução William Weaver. New York: Harcourt Brace Jovanovich, 1981.

CALVINO, Italo. O castelo dos destinos cruzados. São Paulo: Companhia das Letras, 2006.

CALVINO, Italo. Se um viajante numa noite de inverno. São Paulo: Companhia das Letras, 2005.

CALVINO, Italo. Seis propostas para o novo milênio. São Paulo: Companhia das Letras, 2003.

CALVINO, Italo. Um general na biblioteca. São Paulo: Companhia das Letras, 2001.

DAVIS, Robin Camille. Appendices. 2018a. Disponível em: https://bit.ly/2XzwqpI. Acesso em: 29 jul. 2020.

DAVIS, Robin Camille. If on a Winter's Night a Library Cardholder. 2016.

Disponível em: https://bit.ly/3ic31IT. Acesso em: 20 jul. 2020.

DAVIS, Robin Camille. README.md. 2018b. Disponível em: https://bit.ly/2DCnJnA. Acesso em: 22 jul. 2020.

GOLDSMITH, Kenneth. Uncreative Writing. New York: Columbia University, 2011.

HAYLES, Katherine. Literatura eletrônica: novos horizontes para o literário. São Paulo: Global, 2009.

MORETTI, Franco. Distant Reading. London: Verso, 2013.

MORETTI, Franco. Graphs, maps, trees: Abstract models for literary history. London: Verso, 2007.

NaNoGenMo. n.d. Disponível em: https://bit.ly/3fGuke4. Acesso em: 20 jul. 2020.

PERLOFF, Marjorie. Unoriginal Genius: Poetry by Other Means in the New Century. Chicago: University of Chicago, 2012.

QUENEAU, Raymond. Cent mille milliards de poèmes. Paris: Gallimard, 1961.

QUENEAU, Raymond. Exercices de style. Paris: Folio, 1982. 
QUENEAU, Raymond. Un conte à votre façon. In: OULIPO. La littérature potentielle. Paris: Gallimard, 1973.

RETTBERG, Scott. Electronic Literature. Cambridge: Polity, 2019.

SINCLAIR, Stéfan; ROCKWELL, Geoffrey. Voyant Tools. Disponível em: https://voyant-tools.org/. Acesso em: 04 ago. 2020.

\section{NOTAS DE AUTORIA}

Vinícius Carvalho Pereira (viniciuscarpe@gmail.com) é Professor do Departamento de Letras e do Programa de Pós-Graduação em Estudos da Linguagem na UFMT. Doutor em Ciência da Literatura pela UFRJ.

Como citar este artigo de acordo com as normas da revista?

PEREIRA, Vinícius Carvalho. Notas sobre o romance generativo "If on a winter's night a library cardholder”. Texto Digital, Florianópolis, v. 16, n. 2, p. 20-42, 2020.

\section{Contribuição de autoria}

Não se aplica.

Financiamento

Não se aplica.

\section{Consentimento de uso de imagem}

Figs. 1 e 2 - Nuvens de palavras dos excertos encaixados em Se um viajante numa noite de inverno e If on a Winter's Night a Library Cardholder. Fonte: elaboração pelo autor com a aplicação Voyant Tools (SICLAIR; ROCKWELL, 2020).

Figuras 3 e 4 - Redes de palavras co-ocorrentes com book* em Se um viajante numa noite de inverno e If on a Winter's Night a Library Cardholder. Fonte: elaboração pelo autor com a aplicação Voyant Tools (SICLAIR; ROCKWELL, 2020).

Aprovação de comitê de ética em pesquisa

Não se aplica.

\section{Licença de uso}

Este artigo está licenciado sob a Licença Creative Commons CC-BY. Com essa licença você pode compartilhar, adaptar, criar para qualquer fim, desde que atribua a autoria da obra.

\section{Histórico}

Recebido em: 06/08/2020.

Aprovado em: 08/08/2020 